Copyright (C) 2015 by Academic Publishing House Researcher

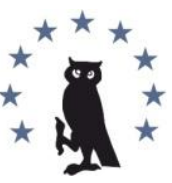

Published in the Russian Federation

European Researcher

Has been issued since 2010.

ISSN 2219-8229

E-ISSN 2224-0136

Vol. 91, Is. 2, pp. 127-133, 2015

DOI: 10.13187/er.2015.91.127

www.erjournal.ru

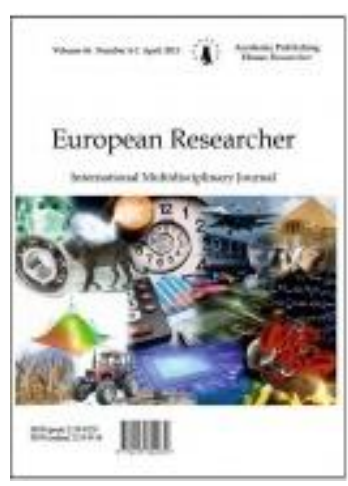

UDC 159.99

\title{
Image-Technologies in the Formation of Female Management Style Features
}

\author{
Anar B. Valiyeva
}

Kazakhstan University for Economics, Finance and International Trade, Kazakhstan Astana city, A. Zhubanova street, 7, 010000

E-mail: valieva.anar@mail.ru

\section{Abstract}

This article targets to reveal attractive invariants in female management style. The author researches the styles and strategies of female management based on two main methods: a) the method of lenient interview, used for specifics of female management detection and evaluation of a woman-in-chief themselves, b) questionnaires of a team management and the personnel of the companies about the level of satisfaction with the management and features of the female head.

Keywords: female management; gender politics; attraction; carrier; imageology; imagetechnologies.

\section{Введение}

При проведении как интервью, так и анкетного опроса не акцентировалось внимание на задаче изучения именно женского менеджмента, чтобы не вызвать дополнительных ассоциаций противопоставления, была предложена более нейтральная позиция, при этом респондентам объяснялось, что изучаются технологии управления казахстанскими компаниями на современном этапе.

В процессе интервью диалог концентрировался вокруг четырех основных аспектах: особенности менеджмента на современных этапе; оптимальные стратегии и стили управления, способствующие успеху компании; оценка собственного стиля управления и его успешности для деятельности компании; оценки степени эффективности менеджмента со стороны персонала и управленческой команды.

Анкетный опрос включал в себя оценку уровня удовлетворенности стилем руководства со стороны персонала и команды, оценку образа эффективного менеджера в сопоставлении с качествами реального руководства, оценку распространенности тех или иных технологий в деятельности женщины топ-менеджера.

В выборку исследования, которое проводилось в 2011-2012 гг., вошли 35 женщинруководителей частных компаний Астаны, в основном обслуживающего профиля (риэлтерские компании, туристские, консалтинговые фирмы, крупные торговые предприятия, в том числе оптовые и др.), с которыми были проведены интервью. Численность персонала в этих организациях составляла от 15 до 87 человек. В 10 компаниях был проведен анкетный опрос членов управленческих команд и персонала. Всего в опросе приняло участие 148 человек - 84 женщины и 64 мужчины. В каждой организации было опрошено от 10 до 18 чел. 


\section{Женский менеджмент в Казахстанских компаниях: аттрактивный имидж женщин-руководителей.}

Смена экономической формации в Казахстане, стремительное развитие института частной собственности, изменения в политике послужило толчком к формированию новой социальной категории людей, добившихся успехов во многом, благодаря своим личным и профессиональным качествам. Это предприниматели, менеджеры, политические лидеры, активно влияющие на экономические и политические процессы в стране. С появлением представителей новой бизнес-элиты в обществе возрос интерес к проблемам карьерного роста. Успешная социальная реализация отдельных руководителей привлекла общественное внимание к механизмам ее осуществление, так появился социальный заказ на исследования в области психологии управления, разработки моделей успешной самопрезентации личности в рамках психологии имиджа. В ситуации некоторой стабилизации экономики в стране, в условиях перехода системы управления из условий «дикого рынка» к «либеральной стабильности», в бизнес кругах, вновь стали значимы представления о морально-этических ценностях, таких как «безупречная репутация» и «позитивное общественное мнение». На сегодняшний момент в обществе сложились уникальные возможности для всестороннего раскрытия потенциала личности проведения работ по изучению формирования новых имидж-технологий, позволяющих создавать позитивный имидж субъекта, в особенности женщины-руководителя, т.к. вопреки конституционным нормам, провозглашенным нашим обществом. И демографическим изменениям, положение женщины в профессиональной сфере продолжает оставаться приниженным, ущемляющим права женщин на рынке труда, не позволяющим ей осуществлять карьерный рост на равноправных позициях с мужчиной.

Поэтому проблема карьерного роста женщины в целом и позитивного имиджа женщины-руководителя в частности, как фактора, способствующего профессиональному продвижению, является социально-значимой на данном этапе развития современного общества.

По мнению некоторых западных авторов [1] существуют "традиционно женские отрасли": общественное питание, бытовое обслуживание, розничная торговля, гостиничное хозяйство и др. Казахстанские исследователи также склонны утверждать, что отраслевая специфика "женского бизнеса" в условиях Казахстана прослеживается достаточно отчетливо. В промышленности, сельском хозяйстве, оптовой торговле, деятельности по обеспечению функционирования рынка, финансовой сфере доля женщинпредпринимателей составляет от 13 \% (в промышленности) до 20 \% (финансы). И наиболее активно осваиваются женщинами розничная торговля, общепит, наука, культура, здравоохранение, где доля предпринимательниц составляет от 39 \% (в розничной торговле) до 56 \% (в науке). Такие выводы согласуются с данными других опросов, что подтверждает их обоснованность [2].

В числе факторов указанной отраслевой специфики, называются причины не только экономического характера. Многие авторы, исследующие данную проблему, склонны отдавать приоритет причинам социально-психологического свойства. Именно они определяют "повышенную проницаемость" бизнеса для женщин в тех сферах, которые требуют в первую очередь терпения, умения договариваться с партнерами, стремления к порядку и "одомашнивания" бизнеса. Однако следует признать. Что по экономическим показателям, а также по численности предприятия, которыми руководят женщины, все таки уступают "мужским". Эта тенденция, впервые выявленная на западных предприятиях, остается значимой и для Казахстана. По оценкам исследователей, этому могут способствовать различные факторы, основными из которых являются следующие: женское предпринимательство сконцентрировано в отраслях, технология которых не предполагает многочисленности работников; женщины-предприниматели более ориентированы на контроль за своим временем, иногда в ущерб росту прибыли, и попытка найти удачный баланс между работой и домом выступает ограничителем расширения масштаба предприятия (причем это не чисто казахстанское явление); скромный размер женского бизнеса во многом определяется "незначительным возрастом" возглавляемых женщинами предприятий. Наиболее интенсивно женщины вторгаются в предпринимательскую деятельность в течение последних двух лет, что связано со значительным снижением 
неопределенности "правил игры" бизнес-среды и непредсказуемости последствий участия в ней. Так, по данным анкетного опроса, среди пришедших в бизнес в начале 2000 г. женщины составили более трети (33\%), а в 2011 гг. их доля среди пополнивших руководящий корпус была почти в два раза меньше (17\%).

Однако социально-экономические объяснения данного феномена должны дополняться, на мой взгляд, анализом особенностей женского менеджмента, его технологий, что позволит значительно расширить потенциал объясняющих гипотез за счет социально-психологических, а не только социально-экономических факторов.

Рассмотрим понятие имиджа. В современной науке «имидж» стал предметом социального интереса и научно-психологического исследования в середине 1980-х гг. Возникновению повышенного интереса к проблеме имиджа способствовали изменения социально-экономических условий жизни общества в конце XX века, развитие в стране рыночной экономики, составляющими которой являются конкуренция и борьбе за рынки сбыта, что в свою очередь привело к бурному развитию PR-технологий, практического имиджмейкинга, дизайна и других прикладных направлений, связанных с продвижением товаров и услуг в условиях конкуренции.

Практический запрос на разработку проблем имиджа и породил новую науку «имиджелогию», которая возникла на стыке философии, психологии, социологии, политологии, культурологи, экономики, костюмологии, истории и других дисциплин [3].

Предметом имиджелогии является «изучение роли и функций имиджей в общественном бытие, их филогенетических и онтогенетических предпосылок, условий, движущих сил и закономерностей формирования, функционирования, управления, а также описание и раскрытие причинно-следственных взаимосвязей между различными имиджами (людей, организаций, общественной и политических движений, товаров, услуг и др. [4]

Многие справочные издания раскрывают содержание понятия имидж, трактуя его как «целенаправленно формируемый образ» [5]; как «сложившийся в массовом сознании и имеющий характер стереотипа эмоционально окрашенный образ» [6]; как «набор определенных качеств, которые люди ассоциируют с определенной индивидуальностью» или как «мысленное представление чего-то ранее видимого конкретного или абстрактного, сильно напоминающего в представлении о другом».

Имидж успешного руководителя в современной социальной психологии рассматривается в рамках психологии управления и анализируется в контексте следующих проблем: формирование имиджа организации; влияние имиджа на деловые отношения, взаимосвязь профессиональных и личностных качеств имиджа руководителя, восприятие управленческой команды, восприятие руководителя, представление об идеальном руководителе, коммуникативные качества руководителей, психологических особенностей личности руководителя, психологических особенностей профессиональной деятельности руководителя, гендерного аспекта в сфере правлении, гендерных особенностей поведения, связанных с личностью современного менеджера, вопросов межличностного восприятия в группе, семантики межличностного общения, гендерного и этнического аспекта, психологии лидерства и др.

Имидж руководителя - это «интегральная, индивидуальная характеристика его управленческих (профессиональных) и личностных качеств, которая в виде целостного образа отображается у членов коллектива и других лиц, находящихся в прямом и косвенном взаимодействии» [2].

\section{Обсуждение}

Современные исследования В.А. Лабунской, Л.Г. Лаптева, Е.А. Петровой, Е.Б. Перелыгиной и т.д. В области имиджелогии показывают, что при формировании имиджа нельзя учитывать влияние стереотипов, сформировавшихся в обществе. На современном этапе в обществе достаточно распространенным является мнением о превосходстве мужчины над женщиной. Эта установка возникла достаточно давно. Так например, в книге «Пол и характер», первый перевод которой появился на русском языке в 1912 году, О. Вайнингер, говоря о различиях в психологии мужчин и женщин, 
отметил у последних отсутствие ума, характера и воли. Это приводит к тому, что женщина никогда не может понять мужчину, который всем этим обладает».

O «хронической» неизменности стереотипов социальной роли женщины в обществе с традиционным укладом пишет В.А. Лабунская в книге 2001 года «Социальная психология личности в вопросах и ответах» и приводит исторический обзор мнений зарубежных исследователей по данной проблеме. Она говорит, что еще в конце 50-х годов Макки, Шеррифс, О”Лири, указывали, что в рамках традиционной европейской культуры мужской образ характеризуется такими чертами, как: компетентность, рациональность, активность и эффективность, социально неограниченный стиль поведения [7].

Типично женскому образу, напротив, приписываются такие черты, как: эмоциональная поддержка, теплота чувств, высокий уровень эмпатии, направленность на социально-коммуникативные умения. Таким образом, традиционно в целом мужчины имели больше положительных качеств, чем женщины, и при этом успехи мужчин в профессиональной сфере чаще объясняются их способности, в то время как успехи женщин - случайностями и другими «нестабильными причинами» [8].

Психологами отмечается тот факт, что в консервативном обществе для женщин компетентность в личностном плане оказывается отрицательным качеством. Высококомпетентные женщины специалисты не пользуются особым расположением ни женщин, ни мужчин, поскольку это нарушает иерархию взаимоотношений между мужчиной и женщиной и опровергает сложившиеся стереотипы. Данное явление нашло подтверждение в исследованиях Р. Хаген, А. Кан (1975). Они обнаружили, что в условиях, и кооперативного, и соревновательного взаимодействия мужчины и женщины стремятся исключить из своей группы компетентных женщин [9].

Исследования в этой области показывают, что без положительного делового имиджа становится невозможным серьезное карьерное продвижение и приобретение авторитета в деловых кругах. Имидж деловой женщины - это сложное создание неповторимого, органичного, целостного и гибкого образа, постоянное поддерживание внимания к нему. Имидж должен формироваться по двум основным направлениям: 1. Соответствие требованиям канала массовой коммуникации (ТВ, пресса). Это аудио- и визуальная информация: манера одеваться, говорить. Это - прическа, взгляд, поза, жесты, мимика, то есть $69 \%$ информации о человеке, которая не дублируется в словах. 2. Характеристики, которое деловое окружение считает важными, - образ мыслей, интеллект, интересы, ценности, хобби, тезаурус понятий и идей. Это - профессионализм, доверие, авторитет. То есть личностные характеристики, оценивающиеся окружающими позитивно. Удачный деловой имидж влияет не только на восприятие личности деловым окружением, но и на восприятие личности самой себя. Э. Семпсон личностный имидж определяет как сочетание ряда внешних и внутренних факторов, задающих самоимидж, который отражает состояние самоуважения, воспринимаемый имидж, то есть представление окружающих о личности и требуемый имидж, который предполагает соответствие определенным имиджевым характеристикам. Личностный имидж воздействует на личность в той же степени, в какой он воздействует и на окружающих его людей.

Выделяют целый ряд принципов построения делового имиджа. К основным принципам относятся: 1) реалистичная, непредвзятая самооценка; 2) учет ожиданий делового окружения; 3) ясные, четко сформулированные цели; 4) изменение собственного имиджа в сторону большего профессионализма; 5) создание делового имиджа во многих направлениях; 6) соответствие основным параметрам выбранного имиджа.

Гибких творческих технологий в условиях кризиса требуют не только конфликтные ситуации. Важнейшая составляющая профессионализма женщин-лидеров - умение вести переговоры без поражения для себя и для партнеров. "Наши партнеры за столом, как справедливо отмечает одна из руководительниц, - обладают эмоциями, глубокой приверженностью к определенным ценностям, различными взглядами. Более того, они непредсказуем. Этот факт может быть полезным или разрушительным для переговоров. Все зависит от того, насколько вы умеете его заставить работать на достижение целей". 


\section{Выводы}

Итак, проведенное исследование позволяет утверждать, что женщины-руководители совсем не стремятся в бизнес-деятельности к повышенной открытости и излишней щедрости, предпочитая более умеренные оценки подобных качеств. Одновременно они демонстрируют высокие этические стандарты, предпочитая “честные" отношения "лживым". Как следует из полученных результатов, такие личностные качества в картине самооценки, как скромность, честность и приветливость, получили $50 \%$ и более в максимальных оценках (5 баллов). Максимальные оценки были поставлены и таким деловым качествам, как трудолюбие, ответственность и уравновешенность. Наименьшее число максимальных оценок получили: активность, щедрость, доверчивость и открытость. Таким образом, бытующее в массовом сознании представление о том, что женщина - более мягкий и доверчивый менеджер, не подтверждается оценками, которые сами руководительницы дают своим качествам и стилю управления.

И хотя идеальный образ смещен у женщин в сторону гуманного менеджера, собственный стиль управления, который они вынуждены реализовывать в конкретной жизни компании, подобным образом можно охарактеризовать лишь отчасти.

Анкеты, по сути, представляют собой оценочные шкалы, состоящие из 18 парных качеств личности. В левой части содержится негативный набор личностных качеств, справа - позитивный. В задачу респондентов входило оценить степень выраженности названных качеств у успешного менеджера, у себя лично или у руководителя и успешного менеджера в случае, когда его оценивали члены управленческой команды, персонал. Опрошенные проставляли соответствующий балл (от 1 до 5).

\section{Примечания:}

1. Агеев В.С. Межгрупповое взаимодействие: Социально-психологические проблемы. М.: Изд-во МГУ, 1990. 240 с.

2. Абульханова-Славская К.А. Взаимосвязь профессиональных и личностных качеств имиджа руководителя: дис. ... канд. психол. наук: Казань, 2002. 179 с.

3. Бриджан Е.С. Имидж деловой женщины как фактор карьерного продвижения // «Имиджелогия - 2005»: феноменология, теория, практика: Материалы 2-го Межд. симпозиума по имиджелогии / Под ред. Е.А. Петровой. М.; РИЦ АИМ. М., 2005. С. 251-254.

4. Петрова Е.А. Псиносемиотика предметной среды как фактор формирования персонального имиджа: дис. ... доктора псих. наук: Москва. 2003. 166 с.

5. Прохоров А.М. Советская энциклопедия. М.: 1981. 1600 с.

6. Фридман Л.М. Психологический справочник учителя. М.: Издание Просвещение, 1991. $288 \mathrm{c}$.

7. Лабунская В.А. Психология затрудненного общения. М.: 2013.

8. Kiesler S.B. Actuarial prejudice towards women and its implication // J. of Appl. Soc. Psychol. 1975. V. 5. P. 98-110.

9. Hagen R.L., Kahn Л. Discrimination against competent women // J. of appi. social psychology. 1975. V. 5. № 4. P. 362-376.

10. Миллер В.К. Англо-русский словарь. М.: ОГИЗ, 1948.

11. Борисов Б.Л. Реклама, паблик релейшинз. Алхимия власти. М.: ИНФРА-М, 1998.

12. Браун Л. Имидж - путь к успеху. СПб.: Питер, 2000. 192 с.

13. Вейнингер О. Пол и характер. Принципиальные исследования / Пер. с 10-го нем. изд. С. Пресса / Под ред. А. Грена. 3-е изд. М.: Сфинкс, 1909. 420 с.

14. Быков А.В. Ораторское искусство и пластическая выразительность как средства достижения карьерного роста политика // Имиджелогия - 2004: состояние, направления, проблемы: Материалы 2-го Междунар. симпозиума по имиджелогии / Под ред. Е.А. Петровой. М.: РИЦ АИМ, 2004. 374 с.

15. Веретенникова И.В. Влияние имиджа человека на деловые отношения в организации: дис. ... канд. псих. наук. М., 2001. 125 с.

16. Шкурко Н.М. Значение имиджа для успешного создания карьеры // Имиджелогия - 2004: состояние, направления, проблемы: Материалы 2-го Междунар. симпозиума по имиджелогии / Под ред. Е.А. Петровой. М., 2004. С. 161-164.

17. Современный словарь иностранных слов. М., 1997. 229 с. 
18. Стрекалова Н.Д. Социально-психологическая типология активности женщины: дис. ... канд. психол. наук. М., 1999. 179 с.

19. Pheterson G.I., Kiesler S.B., Goldberg P.-A. Evaluation of the performance of women as a function of their sex, achiev-ment and personal history //J. ef Pers. and Soc. Psychol. 1971. V. 19. P. 234-241.

\title{
References:
}

1. Ageev B.C. Mezhgruppovoe vzaimodeistvie: Sotsial'no-psikhologicheskie problemy. M.: Izd-vo MGU, 1990. $240 \mathrm{s.}$

2. Abul'khanova-Slavskaya K.A. Vzaimosvyaz' professional'nykh i lichnostnykh kachestv imidzha rukovoditelya: dis. ... kand. psikhol. nauk: Kazan', 2002. 179 s.

3. Bridzhan E.S. Imidzh delovoi zhenshchiny kak faktor kar'ernogo prodvizheniya // «Imidzhelogiya - 2005»: fenomenologiya, teoriya, praktika: Materialy 2-go Mezhd. simpoziuma po imidzhelogii / Pod red. E.A. Petrovoi. M.; RITs AIM. M., 2005. S. 251-254.

4. Petrova E.A. Psinosemiotika predmetnoi sredy kak faktor formirovaniya personal'nogo imidzha: dis. ... doktora psikh. nauk: Moskva. 2003. $166 \mathrm{~s}$.

5. Prokhorov A.M. Sovetskaya entsiklopediya. M.: 1981. 1600 s.

6. Fridman L.M. Psikhologicheskii spravochnik uchitelya. M.: Izdanie Prosveshchenie, 1991. $288 \mathrm{c}$.

7. Labunskaya V.A. Psikhologiya zatrudnennogo obshcheniya. M.: 2013.

8. Kiesler S.B. Actuarial prejudice towards women and its implication // J. of Appl. Soc. Psychol. 1975. V. 5. P. 98-110.

9. Hagen R.L., Kahn L. Discrimination against competent women // J. of appi. social psychology. 1975. V. 5. № 4. P. 362-376.

10. Miller V.K. Anglo-russkii slovar'. M.: OGIZ, 1948.

11. Borisov B.L. Reklama, pablik releishinz. Alkhimiya vlasti. M.: INFRA-M, 1998.

12. Braun L. Imidzh - put' k uspekhu. SPb.: Piter, 2000. $192 \mathrm{~s}$.

13. Veininger O. Pol i kharakter. Printsipial'nye issledovaniya / Per. s 10-go nem. izd. S. Pressa / Pod red. A. Grena. 3-e izd. M.: Sfinks, 1909. 420 s.

14. Bykov A.V. Oratorskoe iskusstvo i plasticheskaya vyrazitel'nost' kak sredstva dostizheniya kar'ernogo rosta politika // Imidzhelogiya - 2004: sostoyanie, napravleniya, problemy: Materialy 2-go Mezhdunar. simpoziuma po imidzhelogii / Pod red. E.A. Petrovoi. M.: RITs AIM, 2004. 374 S.

15. Veretennikova I.V. Vliyanie imidzha cheloveka na delovye otnosheniya v organizatsii: dis. ... kand. psikh. nauk. M., 2001. $125 \mathrm{~s}$.

16. Shkurko N.M. Znachenie imidzha dlya uspeshnogo sozdaniya kar'ery // Imidzhelogiya 2004: sostoyanie, napravleniya, problemy: Materialy 2-go Mezhdunar. simpoziuma po imidzhelogii / Pod red. E.A. Petrovoi. M., 2004. S. 161-164.

17. Sovremennyi slovar' inostrannykh slov. M., 1997. $229 \mathrm{s.}$

18. Strekalova N.D. Sotsial'no-psikhologicheskaya tipologiya aktivnosti zhenshchiny: dis. ... kand. psikhol. nauk. M., 1999. $179 \mathrm{~s}$.

19. Pheterson G.I., Kiesler S.B., Goldberg P.-A. Evaluation of the performance of women as a function of their sex, achiev-ment and personal history //J. ef Pers. and Soc. Psychol. 1971. V. 19. P. 234-241.

УДК 159.99

\section{Имидж-технологии в формировании особенностей стиля женского менеджмента}

\author{
Анар Бахытжановна Валиева
}

Казахский университет экономики, финансов и международной торговли, Казахстан г. Астана, ул. А.Жубанова, 7, 010000

Старший преподаватель

E-mail: valieva.anar@mail.ru 
Аннотация. В данной статье автор раскрывает тему имидж-технологий в формировании особенностей стиля именного менеджмента. На сегодняшний момент в обществе сложились уникальные возможности для всестороннего раскрытия потенциала личности при изучении формирования новых имидж-технологий.

Ключевые слова: женский менеджмент; гендерная политика; аттракция; карьерный рост; имиджелогия; имидж-технологии. 